\title{
Innate IgG Molecules and Innate B Cells Expressed by Immunoglobulin Constant Heavy G Chain (FCy) Genetic Marker Genes Are Involved in the 'Allergic March' of IgE Sensitization in Children
}

\author{
Vivi-Anne Oxelius $^{\mathrm{a}}$ Renate Krueger ${ }^{\mathrm{c}}$ Staffan Ahlstedt ${ }^{\mathrm{b}}$ Thomas Keil $^{\mathrm{d}}$ \\ Susanne Lau ${ }^{c}$ Ulrich Wahn ${ }^{c}$ \\ a Department of Pediatrics and Institute of Laboratory Medicine, Department of Clinical Immunology, University \\ Hospital, Lund University, Lund, and ${ }^{\mathrm{b} C}$ enter of Allergy Research, National Institute of Environmental Medicine, \\ Karolinska Institute, Stockholm, Sweden; ${ }^{C}$ Department of Pediatric Pneumology and Immunology and ${ }^{\mathrm{d}}$ Institute of \\ Social Medicine, Epidemiology and Health Economics, Charité University Medical Centre, Berlin, Germany
}

\section{Key Words \\ Immunoglobulin constant heavy $G$ chain ( $F(\gamma)$ genetic marker genes · Innate lgG subclass molecules · Innate $B$ cells $\cdot \lg$ sensitization at 1 and 10 years of age}

\begin{abstract}
Background: Interindividual variations of immunoglobulin constant heavy $\mathrm{G}$ chain (IGHG) genes on chromosome $14 q 32.3$ are identified by alternative genetic markers (GM) of $\lg G 3$, lgG1 and $\lg G 2$, respectively. They express structurally and functionally innate $\lg \mathrm{G}$ molecules and B cells, associated with allergic disease, replicated in several studies. Materials and Methods: 1-year-old and 10-year-old, IgE-sensitized and non-sensitized children from the German Multicenter Allergy Study birth cohort were assessed by new serological methods for the mendelian /GHG (Fcy) (GM) genes, as innate IgG molecules and innate B cells. Results: Food allergy sensitization in thirty-five 1-year-old children (124 not sensitized) was associated with the IGHG*bfn haplotype and $\mathrm{B}^{* \mathrm{bfn}}$ cells (OR 1.9, 95\% Cl 1.2-3.1; $p=0.010)$. Aeroallergen sensitization in ninety-nine 10-year-old children (95 not sensitized) was associated with the same genes (OR 1.4, 95\% Cl 1.02-1.9; $p=0.034)$. The $\lg E$ sensitization was most prominent in the
\end{abstract}

restrictive homozygous $1 G H G^{*} b f n / * b f$ diplotype, $34 \%$ at age 1 , increasing to $60 \%$ at age 10 , rating the highest numbers of positive lgE tests, expressing increased levels of IgE and innate IgG2*n. Conclusions: The IGHG*bfn haplotype ( $B^{* b f n}$ cells) and increased innate lgG $2 * n$ levels are predictive factors for IgE sensitization in childhood. IGHG genes can be assessed for prognostic and preventive purposes in clinical care.

(c) 2015 S. Karger AG, Basel

\section{Introduction}

Several candidate genes have been found associated with the inflammatory response of IgE-mediated allergy [1-3]. Asthma and allergy are linked to the IGHG $(\mathrm{Fc} \gamma)$ (genetic marker, GM) genes, replicated in several studies by serological methods [4-7]. Serological IGHG gene mapping, based on alternative mendelian GM allotypes of $\gamma 3, \gamma 1$ and $\gamma 2$ on chromosome 14q32.3 (5' $-\mu, \delta, \gamma 3, \gamma 1$, $\left.\psi \varepsilon, \alpha 1, \gamma 2, \gamma 4, \varepsilon, \alpha 2-3^{\prime}\right)$, have identified new innate $\operatorname{IgG}$ subclasses and new $\mathrm{B}$ cells. There is no genetic marker for IgE but IgG genes are informative. $I G H G(\mathrm{Fc})(\mathrm{GM})$ genes are associated with allergen IgE sensitization [8-14]. Ge-

\section{KARGER 125}

(c) 2015 S. Karger AG, Base

$1018-2438 / 15 / 1661-0025 \$ 39.50 / 0$ 
nome-wide association studies have not included GM genes in their genotyping platform [15-17] and have missed IGHG as candidate gene.

The alternative GM allotypes are for $\gamma 3$-chains $* b / 5$ and/or $* \mathrm{~g} / 21$, for $\gamma 1$-chains $* \mathrm{f} / 3$ and/or $* \mathrm{a} / 1$, and for $\gamma 2$ chains ${ }^{*}$ /23 and/or ${ }^{*}-\mathrm{n} /-23$. There are 10 homozygous and heterozygous individual $I G H G$ diplotypes, made up by combinations of 4 fixed $I G H G$ haplotypes: $I G H G^{*} b f n$, $I G H G^{*} b f-n, I G H G^{*} g a n$ and $I G H G^{*} g a-n$, markers of Bcell variants: $B^{* b f n}(B 1), B^{* b f-n}(B 2), B^{* g a n}(B 3)$ and $B^{* \text { ga-n }}$ (B4) [14]. The IGHG gene complex, dissected in alleles (allotypes), genotypes, haplotypes and diplotypes and innate IgG subclass levels are registered $[18,19]$. A gene map and reference serum levels of healthy Caucasians are given (see online suppl. addendum; for all online suppl. material, see www.karger.com/doi/10.1159/000371351).

The innate alternative IgG subclass variants differ by structure and function, by amino acids [5], by electrophoretic and chromatographic rates [20], by developmental rate during childhood [19], by half-life times [21], by different results on vaccination $[22,23]$ and treatment with monoclonal humanized antibodies [24]. Allergens, bacteria $[22,23]$ and virus [25-27] affect IGHG genes of individuals differently and relate to the diseases as allergy [7-12], primary immunodeficiency [28], autoimmunity $[29,30]$ and malignancy $[31,32]$.

Restrictive IGHG genes are found in patients with clinical allergy, increased IgE levels, increased IgG4 levels, with a family history of allergy and in technicians exposed to laboratory animals developing laboratory animal allergy [7-10]. The IGHG genes are linked to different phenotypes of childhood asthma: the IGHG* $b f n$ to IgE-mediated and the $I G H G^{*} b f-n$ and $I G H G^{*} g a-n$ to infectionprone asthma, combined with low levels of IgG [7].

The aim of the study was to investigate, if $I G H G$ genes can predict the development of atopy in children. The rate of food and aeroallergen IgE sensitization was investigated in $I G H G$ diplotypes, IGHG haplotypic B cells, IGHG2 genes and IgG subclass levels of children aged 1 and 10 years, from the Multicenter Allergy Study (MAS). The serum levels of innate IgG subclass molecules were assessed [7] in 10-year-old IgE-sensitized children.

\section{Materials and Methods}

\section{Study Population}

The study population comprised 194 Caucasian children from the German MAS birth cohort, with case and controls from the same group of patients. Details of recruitment and the study subjects have been reported previously [33]. For the present analyses, we used data on allergic sensitization from the 1-year and 10-year follow-up assessments. The research protocol was approved by the ethical review board of the coordinating center (Charité University Medical Center, Berlin, Germany).

\section{Assessment of Allergic Sensitization}

Specific sensitization to 4 food allergens (hen's egg, cow's milk, soy and wheat) and 5 common indoor and outdoor aeroallergens (house dust mite, cat, dog, birch pollen and timothy grass pollen) was assessed as specific IgE antibodies in blood of 1- and 10-yearold children, respectively, by utilizing ImmunoCAP (Phadia AB, Uppsala, Sweden). Children were regarded as sensitized if the specific IgE to at least 1 allergen was $\geq 0.35 \mathrm{kU} / \mathrm{l}$. The analyses were performed by Phadia Laboratories in Berlin.

\section{IGHG Genotyping and Quantification of Innate IgG Subclass}

Levels

The IGHG genes were assessed by serological IGHG $(\mathrm{Fc} \gamma)$ (GM) gene mapping based on alternative GM allotypes for quality and quantity. The GM allotypes are genetic markers on the constant heavy $\mathrm{G}$ chains, the Fc part of the molecule. The alternative allotypes of $\gamma^{3}, \gamma 1$ and $\gamma^{2}$ are distinctive unique entities with different structures and functions. IGHG genes and innate IgG subclasses were investigated for quality and quantity with new serological methods: competitive ELISA, double immunodiffusion, Mancini technique $[6,13]$.

Sera from a hundred and ninety-four 10-year-old and a hundred and fifty-nine 1-year-old children from the MAS were genotyped defining individual $I G H G$ diplotypes, $I G H G$ haplotypes (Bcell variants), $I G H G$ subclass genotypes and alternative $I G H G$ allotypes (alleles). The very rare diplotypes (totally $<1-2 \%$ of Caucasians) were left out. By the tests the quantitative expressions of IGHG genes are available. Total IgG subclass levels were measured with the Mancini technique. Innate IgG subclass levels were assessed in IgE-sensitized patients with homozygous $I G H G^{*} b f n /$ *bfn diplotypes and heterozygous $I G H G^{*} b f n /{ }^{*} b f-n$ and compared to not sensitized age- and $I G H G$-matched children from the MAS.

\section{Statistical Analysis}

The data were analyzed by the SPSS statistical package, SPSS $11.5, \chi^{2}$ test and 2 by 2 tables employing the 'Wald' approximation of the variance of the odds ratios (OR), similar to simple logistic regression with an estimate of the OR for the final model variables and associated $95 \%$ confidence intervals (CI). A p value $<0.05$ was considered statistically significant. The serum levels of allelic innate IgG subclasses of IgE-sensitized patients with the $I G H G^{*} b f n /{ }^{*} b f n$ and $I G H G^{*} b f n{ }^{*} b f-n$ diplotypes were compared to nonsensitized age- and IGHG- matched controls with the z-test.

\section{Results}

\section{The 'Atopic March' in IGHG Diplotypes, IGHG}

Haplotypes and IGHG2 Genotypes

The IgE sensitization rate for children at 1 and 10 years of age, the 'atopic march', was recorded. The atopic march was most prominent within the homozygous $I G H G^{*} b f n /{ }^{*} b f n$ (B1/B1) diplotype, with an increase 
from $12 / 35=34 \%$ to $27 / 45=60 \%$ sensitized (online suppl. table 1). The various specific allergen sensitizations within homozygous $I G H G^{*} b f n /{ }^{*} b f n$ were rated from 38 to $60 \%$ in 1-year-old and from 25 to $39 \%$ in 10 -year-old children, respectively. The remaining 2 homozygous diplotypes showed lower rates of sensitization, IGHG* $b f$ $n /{ }^{*} b f-n(\mathrm{~B} 2 / \mathrm{B} 2)$ from $0 / 7=0 \%$ to $6 / 9=67 \%$ and $I G H G^{*} g a-$ $n /{ }^{*}$ ga-n (B4/B4) from $1 / 19=5 \%$ to $9 / 21=43 \%$, respectively. The specific allergen sensitization within $I G H G^{*} b f-n /{ }^{*} b f-n$ was $0 \%$ in 1 -year-olds and $0-7 \%$ in 10 -year-olds and within $I G H G^{*} g a-n /{ }^{*} g a-n \quad 0-4 \%$ in 1 -year-olds and $8-15 \%$ in 10 -year-olds, respectively. Thus, the $I G H G 2^{*}-n{ }^{*}-n$ was not involved in the food sensitization but to some degree in aeroallergen sensitization. IgE sensitization was increased within the homozygous $I G H G 2^{*} n /{ }^{*} n\left(I G H G^{*} b f n /{ }^{*} b f n\right)$ genotype compared to the opposite IGHG2*-n/*-n, containing IGHG*bf-n and $I G H G^{*} g a-n$ haplotypes (OR 2.9, 95\% CI 1.1-7.2; p = 0.022 ). The atopic march for cat allergy was most prominent for $I G H G^{*} b f n /{ }^{*} b f n$ : 2 in 1-year-olds and rising to 15 in 10-year-olds, compared to the other homozygous diplotypes for $I G H G^{*} b f-n /^{*} b f-n$ from 0 to 1 and for $I G H G^{*} g a-n /{ }^{*} g a-n$ from 0 to 3 in 1 - and 10 -year-olds, respectively (online suppl. table $1 \mathrm{a}, \mathrm{b}$ ).

\section{IgE Sensitization in IGHG Haplotypes (Innate B}

Cells) and IGHG2 Alleles (Innate IgG2* $n$ and IgG2*-n Molecules)

Of 35 sensitized (70 IGHG haplotypes) 1-year-old children, the $I G H G^{*} b f n$ haplotype, $\mathrm{B}^{* \mathrm{bfn}}$ (B1) cells and the $I G H G 2^{*} n$ allele frequencies were significantly increased, in all sensitized $(\mathrm{n}=41$, OR 1.9, 95\% CI 1.2-3.1; $\mathrm{p}=0.010)$ and in specific hen's egg-sensitized $(\mathrm{n}=32$, OR $2.7,95 \%$ CI 1.4-4.9; $\mathrm{p}=0.001)$, in milk-sensitized $(\mathrm{n}=23$, OR 2.0, 95\% CI 1.1-4.0; $\mathrm{p}=0.031)$ and in wheat-sensitized children $(\mathrm{n}=16$, OR 5.3, 95\% CI 1.8-16.0; $\mathrm{p}<0.001)$ compared to 124 nonsensitized ones (online suppl. tables $2 \mathrm{a}$, $3 a)$. The opposite $I G H G^{*} g a-n$ haplotype and $\mathrm{B}^{* \mathrm{ga}-\mathrm{n}}(\mathrm{B} 4)$ cells with the IGHG2*-n allele were instead significantly decreased in all sensitized children $(\mathrm{n}=14$, OR $0.5,95 \%$ CI 0.3-0.9; $\mathrm{p}=0.030$ ).

Of 99 sensitized 10-year-old children (198 IGHG haplotypes), the $I G H G^{*} b f n$ haplotype, $\mathrm{B}^{* \mathrm{bfn}}$ (B1) cells and the $I G H G 2^{*} n$ allele frequencies were significantly increased in all sensitized $(\mathrm{n}=101$, OR 1.4, 95\% CI 1.02-1.9; $\mathrm{p}=$ 0.034 ; online suppl. tables $2 \mathrm{~b}, 3 \mathrm{~b}$ ) and in specific birchsensitized ( $\mathrm{n}=61$, OR 2.0, 95\% CI 1.3-3.0; $\mathrm{p}<0.001)$, in grass-sensitized $(\mathrm{n}=77$, OR 1.4, 95\% CI 1.0-2.0; $\mathrm{p}=$ $0.050)$, in cat-sensitized ( $\mathrm{n}=45$, OR $1.9,95 \%$ CI 1.2-3.1; $\mathrm{p}=0.006)$ and in dog-sensitized $(\mathrm{n}=46, \mathrm{OR} 1.4,95 \%$ CI

IGHG(GM) Genes and IgE Sensitization at Different Ages
$1.02-1.9 ; \mathrm{p}=0.034)$ compared to 95 nonsensitized children (online suppl. tables $2 \mathrm{~b}, 3 \mathrm{~b}$ ). In this age group, the frequency of the opposite $I G H G^{*} g a-n$ haplotype and $\mathrm{B}^{* \mathrm{ga}-\mathrm{n}}$ (B4) cells did not differ when compared to nonsensitized children. The IGHG gene frequencies of 124 of the 1 -year-old and of 95 non-IgE-sensitized 10-year-old children did not deviate from those of a healthy Caucasian population (Hardy-Weinberg equilibrium $\mathrm{p}>0.5$; online suppl. material, gene map).

\section{Positive IgE Tests Associated with IGHG2*n Alleles}

Next, we investigated the quality of IgE sensitization by the numbers of positive IgE tests per person, at different ages. We found that carriers of the homozygous $I G H G^{*} b f n /{ }^{*} b f n$ including homozygous IGHG2* $n /{ }^{*} n$ had higher numbers of positive IgE tests than carriers of the alternative $I G H G 2^{*}-n /{ }^{*}-n 2.3$ versus 1.0 positive tests per patient in 1-year-olds and 4.5 versus 3.2 positive tests per patient in 10-year-olds.

Increased Innate IgG2*n Subclass Levels in IgE-Sensitized Individuals with the Homozygous $I G H G^{*} b f n /{ }^{*} b f n$ and Heterozygous IGHG* $b f n /{ }^{*} b f-n$ Diplotypes

Twenty-seven IgE-sensitized 10-year-old children compared to 18 nonsensitized ones, with homozygous $I G H G^{*} b f n /{ }^{*} b f n$, demonstrated significantly increased amounts of the allelic innate IgG2*n subclass $(1.21 \pm 0.43$ $\mathrm{g} / \mathrm{l})$ and $\operatorname{IgE}(567.29 \pm 630.31 \mathrm{kU} / \mathrm{l})$ levels compared to nonsensitized $\operatorname{IgG} 2 * \mathrm{n}(0.92 \pm 0.44 \mathrm{~g} / \mathrm{l})$ and $\operatorname{IgE}(25.20 \pm 20.48$ $\mathrm{kU} / \mathrm{l}$ ), respectively (online suppl. table 4). Also $26 \mathrm{IgE}$-sensitized compared to 26 nonsensitized heterozygous $I G H G^{*} b f n /{ }^{*} b f-n$ subjects with only $1 I G H G^{*} b f n$ haplotype and 1 IGHG2* $n$ allele demonstrated significantly increased $\operatorname{IgG} 2 * \mathrm{n}(0.70 \pm 0.24 \mathrm{~g} / \mathrm{l})$ and $\operatorname{IgE}(332.97 \pm 314.37 \mathrm{kU} / \mathrm{l}) \mathrm{lev}-$ els compared to $\operatorname{IgG2} * n(0.55 \pm 0.24 \mathrm{~g} / \mathrm{l})$ and $\operatorname{IgE}(45.80 \pm$ $52.95 \mathrm{kU} / \mathrm{l})$, respectively. The level of IgG2*-n was left out.

\section{Discussion}

$I G H G(\gamma)$ genes are in linkage disequilibrium with the $\operatorname{IGHE}(\varepsilon)$ gene on chromosome $14 \mathrm{q} 32.3\left(5^{\prime}-\mu, \delta, \gamma 3, \gamma 1\right.$, $\left.\psi \varepsilon \alpha 1, \gamma 2, \gamma 4, \varepsilon, \alpha 2-3^{\prime}\right)$. In the absence of genetic markers for IGHE, the IGHG genes are informative. The alternative GM allotypes of $\gamma^{3-}, \gamma 1$ - and $\gamma 2$-chains, respectively, were identified with a new sensitive competitive ELISA, defining the interindividual variability of innate IgG subclasses and innate B cells $[13,14]$. The alternative GM allotypes are markers of the $\mathrm{F} c \gamma$ part of the IgG molecules 
which differ by structures and functions [5]. Specific $I G H G$ genes are involved in IgE sensitization of allergy patients [7-12]. Genome-wide association studies and HapMap do not include GM allotypes in their genetic platforms. This has underestimated IGHG as candidate gene in immunobiology and allergy [15-17].

We demonstrate a significant association of $I G H G^{*} b f n$ haplotypes with innate $\operatorname{IgG} 3 * \mathrm{~b}, \operatorname{IgG} 1 * \mathrm{f}$ and $\operatorname{IgG} 2 * \mathrm{n}$ expressed from the innate $\mathrm{B}^{* \mathrm{bfn}}$ (B1) cells, in 1-year-old children IgE sensitized with food allergens and in 10-year-old children IgE sensitized with aeroallergens (online suppl. tables 2,3). IgE sensitization was most prominent in the homozygous $I G H G^{*} b f n /{ }^{*} b f n$ with $I G H G^{*} b f n$ inherited from both parents. The number of IgE sensitized in homozygous $I G H G^{*} b f n /{ }^{*} b f n$ rose from $12 / 35(34 \%)$ in 1-yearolds, to $27 / 45(60 \%)$ in 10-year-olds, demonstrating the 'atopic march'. Homozygous IGHG2* $n /{ }^{*} n$ contained the dominating numbers of positive IgE tests/individual, compared to the opposite homozygous $I G H G 2^{*}-n /{ }^{*}-n$. The innate IgG2*n levels were significantly increased in IgE-sensitized carriers, in homozygous $I G H G^{*} b f n /{ }^{*} b f n$ and heterozygous $I G H G^{*} b f n /{ }^{*} b f-n$, compared to age- and $I G H G$-matched nonsensitized children (online suppl. table 4). Increased innate IgG2*n levels have been recorded in IgE-mediated childhood asthma [7]. The activated $I G H G 2^{*} n$ allele is probably taking part in the IgE sensitization process. The $\gamma 2$-genes are located $18 \mathrm{~kb}$ from the $\gamma 4$ and another $23 \mathrm{~kb}$ from the $\varepsilon$-genes on chromosome $14 \mathrm{q} 32.3$, which part is activated by IL- 4 and IL- 13 cytokines from Th2 lymphocytes [34, 35]. Genome-wide association studies have been rather insufficient to capture causal allergy gene variants. However, recently a finemapping study of IgE-associated loci confirmed and identified single-nucleotide polymorphisms of chromosome $5 q 31$ regulating the Th2 cytokines IL- 4 and IL-13 [36]. The finding of significantly increased IgG2*n levels in IgE-sensitized children is highlighted and must be compared with the slow rate of increasing IgG2*n levels during childhood in healthy children $[7,20]$. The stimulation by allergens of both the $I G H G 2^{*} n$ allele and IGHE genes, avoiding activation of $I G H G 3^{*} b$ and $I G H G 1^{*}$ falleles upstream, known to be activated by infections in healthy controls, might be in agreement with the hygiene hypothesis. The present paradigm dictates that atopy is accomplished mainly by the effect of IGHE, but the whole $I G H$ haplotype, where both $I G H G$ and $I G H E$ genes are involved, gives the particular innate $\operatorname{IgG}$ molecules $\operatorname{IgG} 3 * \mathrm{~b}, \operatorname{IgG} 1{ }^{*}$ f and $\operatorname{IgG} 2 * n$ a role in allergy, probably in the early sensitization process as the $I G H G$ genes are activated before the downstream located $I G H E$. The IGHG*bfn haplotype including the IGHG2*n allele and increased IgG2*n levels are most prominent risk factors for IgE sensitization.

In 1-year-old children, food allergens had affected individuals with the $I G H G^{*} b f n$ haplotype (B1 cells) more often than those with the other haplotypes. A negative association of the opposite IGHG2*- $n$ allele with allergen sensitization was observed. The homozygous IGHG2* $n /{ }^{*}$-n genotype demonstrated a weaker sensitization rate (online suppl. tables 1-3). In 10-year-olds, aeroallergens affected mainly the same IGHG*bfn, but the IgE sensitization was found to some degree also in $I G H G^{*} b f-n$ and $I G H G^{*} g a-n$ haplotypes, with the IGHG2*-n allele (online suppl. tables $1 b, 2 b)$. But when equal numbers of the 6 most common IGHG diplotypes of a childhood asthma cohort were investigated, the homozygous $I G H G^{*} b f n /{ }^{*} b f n$ was linked to atopy and the different homozygous $I G H G^{*} b f-n /{ }^{*} b f-n$ and $I G H G^{*} g a-n /{ }^{*} g a-n$ were linked to low levels of IgE, low IgE sensitization and low levels of innate IgG subclasses as in IgG subclass deficiencies [7].

$\mathrm{B}$ cells are the only cells producing antibodies, and B cells can indirectly be defined by $I G H G$ genes [14]. IGHG genes of B cells are found in all human somatic cells, also stem cells [34]. All genes constituting the IGHG haplotype have an impact on the expressed levels of innate IgG subclasses, as it has been demonstrated in both immunodeficient and healthy individuals $[19,20,28]$. The function of the immunoglobulin $\mathrm{G}$ molecule is related to the constant part of the heavy $\mathrm{G}$ chains, the $\mathrm{Fc} \gamma$ part of the molecule, in parallel to the function of the variable adaptive antibody binding site. The IGHG $(\mathrm{Fc} \gamma)(\mathrm{GM})$ allotypes with epitope differences in the Fc part of the molecule have influence on the outcome of both bacterial and viral infections. Individuals with the $I G H G^{*} b f n$ haplotype are high producers of antibodies against encapsulated bacteria and in vaccination with bacterial polysaccharides $[22,23]$. The influence of viral particles acting as $\mathrm{Fc} \gamma \mathrm{Rs}$ with preference of binding to different $I G H G(\mathrm{~F} c \gamma)$ allotypes [25-27] is important and can be applied also to allergic disease, possibly related to exacerbations. Severe infections in infants with respiratory syncytial virus are associated with the $I G H G^{*} b f-n /{ }^{*} b f-n$ diplotype and the IGHG2*- $n$ alleles [35].

$I G H G$ genes can predict different phenotypes in childhood asthma and must be investigated in other forms of allergy. Active and passive immunotherapy, such as allergy vaccination and treatment with humanized recombinant monoclonal antibodies, affects individuals with different $I G H G$ diplotypes with different results. IGHG genes must be investigated in relation to other genes and biomarkers with a known association to IgE-mediated allergy.
28

Int Arch Allergy Immunol 2015;166:25-29 DOI: $10.1159 / 000371351$
Oxelius/Krueger/Ahlstedt/Keil/Lau/Wahn 


\section{Acknowledgments}

Thanks go to Ann-Margreth Carlsson for skillful technical assistance and Håkan Lövkvist for statistical advice. Sources of funding: grants from the Medical Faculty of Lund University and the University Hospital of Lund, the Swedish Asthma and Allergy Association and the Vardal Foundation, Sweden.

We thank all members of the MAS group and all participating centers for their contributions. The MAS was supported by re- search grants (07015633, 07 ALE 27, 01EE9405/5 and 01EE9406) from the Federal Ministry for Education and Research (BMBF), and by the German National Genome Research Network (NGFN Plus, BMBF), Germany.

\section{Disclosure Statement}

Conflict of interest: none declared.

\section{References}

1 March ME, Sleiman PM, Hakonarson H: The genetics of asthma and allergic disorders. Discov Med 2011;11:35-45.

2 Cookson WO: Genetics and genomics of asthma and allergic diseases. Immunol Rev 2002;190:195-206.

3 Ober C: Perspectives on the past decade of asthma genetics. J Allergy Clin Immunol 2005;116:274-278.

4 Grubb R: The Genetic Markers of Human Immunoglobulins. Berlin, Springer, 1970.

5 Grubb R: Human immunoglobulin allotypes and mendelian polymorphism of the human immunoglobulin genes; in Oss CJ, Regenmortel MHV (eds): Immunochemistry. New York, Dekker, 1994, pp 47-68.

6 Oxelius V-A, Pandey JP: Human immunoglobulin constant heavy $\mathrm{G}$ chain (IGHG) $(\mathrm{Fc} \gamma)(\mathrm{GM})$ genes, defining innate variants of IgG molecules and $\mathrm{B}$ cells, have impact on disease and therapy. Clin Immunol 2013;149: 475-486.

7 Oxelius V-A: From genotypes of immunoglobulin constant heavy $\mathrm{G}$ chain $(I G H G)$ $(\mathrm{Fc} \gamma)(\mathrm{GM})$ genes to phenotypes in childhood asthma. Int Arch Allergy Immunol 2012;159: 94-102.

8 Oxelius V-A, Hultquist C, Husby S: Gm allotypes as indicators of non-atopic and atopic bronchial asthma. Int Arch Allergy Appl Immunol 1993;101:66-71.

9 Oxelius V-A, Sjöstedt L, Willers S, Löw B: Development of allergy to laboratory animals is associated with particular Gm and HLA genes. Int Arch Allergy Immunol 1996;110:73-78.

10 Oxelius V-A: Imbalanced switch of the IGHG (immunoglobulin constant heavy G chain) $\mathrm{Gm}$ (bfn) genes in atopic childhood asthma. Allergy 2000;55:1063-1068.

11 Oxelius V-A, Bråbäck L, Ahlstedt S, Björksten B: Immunoglobulin constant heavy $\mathrm{G}$ chain genes as risk factors in childhood allergies. Clin Exp Allergy 2006;36:1616-1624.

12 Oxelius V-A: Immunoglobulin constant heavy $\mathrm{G}$ subclass genes in asthma and allergy. Immunol Res 2008;40:179-191.

13 Oxelius V-A, Carlsson A-M: Quantitation of Gm allotypes. Scand J Immunol 1993;37:143148.

IGHG(GM) Genes and IgE Sensitization at Different Ages
14 Oxelius V-A: Genetic B cell variation based on Immunoglobulin heavy $\mathrm{G}$ chain $(\mathrm{Gm})$ genes. Scand J Immunol 1999;49:345-346.

15 Pandey JP: Genetic polymorphism of Fc. Science 2006;311:1376-1377.

16 Pandey JP: Genomewide association studies and assessment of risk of disease. N Engl J Med 2010;363:2076-2077.

17 Pandey JP: Candidate gene approach's missing link. Science 2010;329:1148.

18 Oxelius V-A: Serum IgG and IgG subclass contents in different GM phenotypes. Scand J Immunol 1993;37:149-153.

19 Oxelius V-A, Aurivillius M, Carlsson A-M, Musil K: Serum Gm allotype development during childhood. Scand J Immunol 1999;50: 440-446.

20 Oxelius V-A: Preparation of IgG subclass allotypes from polyclonal IgG. Scand J Immunol 1999;49:395-398.

21 Oxelius V-A, Eibl MM: Different Gm allotype levels in human intravenous immunglobulin (IVIG) preparations, survival of foreign $\mathrm{Gm}$ allotypes in immunodeficient patients. Clin Exp Immunol 1996;106:203-207.

22 Pandey JP, Fudenberg HH, Virella G, Kyong CU, Lodholt CB, Galbraith RM, Gotschlich EC: Association between immunoglobulin allotypes and immune responses to Haemophilus influenzae and Meningococcus polysaccharides. Lancet 1979;i:190-192.

23 Ambrosino DM, Schiffman G, Gotschlich EC, Schur PH, Rosenberg GA, de Lange GG, van Loghem E, Siber GR: Correlation between $\mathrm{G} 2 \mathrm{~m}(\mathrm{n})$ immunoglobulin allotype and human antibody response and susceptibility to polysaccharide encapsulated bacteria. J Clin Invest 1985;75:1935-1942.

24 Jefferis R, Lefranc MP: Human immunoglobulin allotypes: possible implications for immunogenicity. MAbs 2009;1:332-338.

25 Namboodiri AM, Budkowska A, Nietert PJ, Pandey JP: $F$ c $\gamma$ receptor-like hepatitis $C$ virus core protein binds differentially to IgG of discordant Fc (GM) genotypes. Mol Immunol 2007;44:3805-3808.

26 Atherton A, Armour KL, Bell S, Minson AC, Clark MR: The herpes simplex virus type $1 \mathrm{Fc}$ receptor discrimination between IgG1 allotypes. Eur J Immunol 2000;30:2540-2547.
27 Pandey JP, Astemborski J, Thomas DL: Epistatic effects of immunoglobulin GM and KM allotypes on outcome of infection with hepatitis C virus. J Virol 2004;78:4561-4565.

28 Oxelius V-A, Ochs HD, Hammarström L: Restricted immunoglobulin heavy $G$ chain genes in primary immunodeficiencies. Clin Immunol 2008;128:190-198.

29 Oxelius V-A, Svantesson H, Carlsson A-M: GM phenotype linkage to subsets of juvenile chronic arthritis (JCA). Scand J Rheum 1993; 22:284-288.

30 Jönsson G, Oxelius V-A, Truedsson L, Braconier JH, Sturfelt G, Sjöholm AG: Homozygosity for the IgG2 subclass allotype G2M(n) protects against severe infections in hereditary C2 deficiency. J Immunol 2006; 177:722728.

31 Pandey JP, Nietert PJ, Klaamas K, Kurtenkov $\mathrm{O}$ : A genetic variant of immunoglobulin gamma2 is strongly associated with immunity to mucin 1 in patients with breast cancer. Cancer Immunol Immunother 2009; 58: 2025-2029.

32 Nakao Y, Matsumoto H, Miyazaki T, Watanabe S, Mukojima T, Kawashima R, Fujita T, Tsuji K: Immunoglobulin $\mathrm{G}$ heavy chain allotypes as possible genetic markers for human cancer. J Natl Cancer Inst 1981;67:47-50.

33 Bergmann RL, Bergmann KE, Lau-Schadendorf S, Luck W, Dannemann A, Bauer CP, Dorch W, Foster J, et al: Atopic diseases in infancy. The German Multicenter Atopy Study (MAS-90). Pediatr Allergy Immunol 1994;5:19-25.

34 Takahashi K, Yamanaka S: Induction of pluripotent stem cells from mouse embryonic and adult fibroblast cultures by defined factors. Cell 2006;126:663-676.

35 Aurivillius M, Oymar K, Oxelius V-A: Immunoglobulin heavy G2 chain (IGHG2) gene restriction in the development of severe respiratory syncytial virus infection. Acta Paediatr 2005;94:414-418.

36 Sharma V, Michel S, Gaertner V, Franke A, Vogelberg C, von Berg A, et al: Fine-mapping of IgE associated loci $1 \mathrm{q} 23,5 \mathrm{q} 31$ and $12 \mathrm{q} 13$ using 1,000 Genomes Project data. Allergy 2014;69:1077-1084. 